\title{
Crescimento, desenvolvimento e produtividade do tomateiro cultivado em substrato com três concentrações de nitrogênio na solução nutritiva
}

\author{
Growth, development and yield of tomato plants grown in substrate under three nitrogen \\ concentrations of the nutrient solution
}

\author{
Jerônimo Luiz Andriolo ${ }^{1}$ Tiago Dal Ross ${ }^{2}$ Márcio Witter ${ }^{3}$
}

\section{RESUMO}

Determinou-se o efeito de três concentrações de $N$ da solução nutritiva sobre o crescimento e produtividade do tomateiro cultivado em substrato, no outono e na primavera. Os experimentos foram conduzidos no interior de um túnel alto de polietileno, no Departamento de Fitotecnia da UFSM, empregando-se o híbrido Monte Carlo. As semeaduras foram feitas em 8 de fevereiro e 5 de julho de 2002 e o plantio no interior do túnel aos 36 e 40 dias após a semeadura, no outono e na primavera, respectivamente. Foi empregada uma sacola para cada planta, contendo $5,5 \mathrm{dm}^{3}$ de substrato comercial (Plantmax $\left.{ }^{\circledR}\right)$, com uma planta por sacola e densidade de 3,3 plantas $\mathrm{m}^{-2}$. Os nutrientes foram fornecidos através de uma solução nutritiva contendo, em mmol $L^{-1}: 5,5$ de $\mathrm{KNO}_{3} ; 1,3$ de $\mathrm{KH}_{2} \mathrm{PO}_{4} ; 2,75$ de $\mathrm{Ca}\left(\mathrm{NO}_{3}\right)_{2} ; 0,75$ de $\mathrm{MgSO}_{4}$, com adição de ferro quelatizado e micronutrientes. $O$ tratamento $T 2$ foi igual a solução de referência, com 11,0 mmolN $\mathrm{L}^{-1}$. No tratamento T1, a concentração de nitrogênio da solução nutritiva foi reduzida para 5,5mmolN $L^{-1}$, enquanto em $T 3$ foi aumentada para $15,16 \mathrm{mmolN} L^{-1}$. $O$ delineamento experimental empregado foi o inteiramente casualizado, com quatro repetições e 15 plantas por parcela. Foi feita análise do crescimento e desenvolvimento mediante coleta de plantas aos 33, 48, 55, 62, 69, 76 e 83 dias após o plantio (DAP), no outono, e aos 55, 62, 69, 78, 85 e 92 DAP, na primavera. A produtividade foi medida através da massa verde de frutos. $O$ número de folhas foi inferior nas plantas de T3, no outono e na primavera, enquanto o número de frutos foi mais elevado nas plantas de T1 no cultivo de primavera. A massa seca de frutos no outono evoluiu sem diferenças significativas entre os três tratamentos. Na primavera, essa variável foi inferior nas plantas de $T 3$ ao final do experimento. A produtividade de frutos atingiu valores médios de 5,4; 5,5 e 5,2kg $\mathrm{m}^{-2}$ no outono e de 6,7; 7,7 e 5,8kg $\mathrm{m}^{-2}$ na primavera, respectivamente para $T 1, T 2$ e T3, com produtividade máxima estimada de $7,8 \mathrm{~kg} \mathrm{~m}^{-2}$ na dose de 9,3 mmolN $L^{-1}$. Concluiu-se que a concentração de $N$ na solução nutritiva afetou o crescimento e a produtividade da cultura do tomateiro em substrato, porém não foi observada resposta similar nos dois ciclos de cultivo.

Palavras-chave: Lycopersicon esculentum, massa seca, fertirrigação, cultivo protegido.

\section{ABSTRACT}

The effect of three $N$ concentrations of the nutrient solution on growth and yield of tomato plants grown in substrate was determined in autumn and spring growing periods. Two experiments were conducted inside a polyethylene tunnel, at Departamento de Fitotecnia - UFSM, using the hybrid Monte Carlo. Sowing was made on February 8 and on July 5, 2002, and planting inside the tunnel 36 and 40 days later, in autumn and spring, respectively. Plants were grown in plastic bags filled with $5.5 \mathrm{dm}^{3}$ of commercial substrate (Plantmax $\left.{ }^{\circledR}\right)$, with one plant per bag and a plant density of 3.3 plants $m^{-2}$. Nutrients were supplied to plants by a complete nutrient solution, with the following composition, in mmol $\mathrm{L}^{-1}$ : 5.5 of $\mathrm{KNO}_{3} ; 1.3$ of $\mathrm{KH}_{2} \mathrm{PO}_{4} ; 2.75$ of $\mathrm{Ca}\left(\mathrm{NO}_{3}\right)_{2} ; 0.75$ of $\mathrm{MgSO}$, with iron chelate and micronutrients. The treatment T2 was the nutrient solution described above, with 11.0mmolN $\mathrm{L}^{-1}$. For treatment $T 1$, the $N$ concentration of the nutrient solution was reduced to $5.5 \mathrm{mmolN} \mathrm{L}^{-1}$, whereas for $T 3$ it was increased to $15.16 \mathrm{mmolN} L^{-1}$. A randomised experimental design was used, with four replications and 15 plants per plot. Plants were harvested at 33, 48, 55, 62, 69, 76 and 83 days after planting (DAP) in autumn, and at 55, 62, 69, 78, 85 and 92 DAP in spring, to measure plant growth and development. Crop yield was determined by fresh weight of fruits. The number of leaves was lower on T3 plants in autumn and spring, whereas the number of fruits was higher on T1 plants in spring. The dynamics of fruit dry mass accumulation did not show significant differences among treatments in autumn. In spring, the lowest value of this variable was recorded on T3 plants. Mean values of fresh fruit weight reached $5.4 ; 5.5$ and $5.2 \mathrm{~kg}$ $\mathrm{m}^{2}$ in autumn, and 6.7; 7.7 and $5.8 \mathrm{~kg} \mathrm{~m}^{-2}$ in spring, for T1 T2

\footnotetext{
${ }^{1}$ Engenheiro Agrônomo, Doutor, Professor Titular, Departamento de Fitotecnia, Universidade Federal de Santa Maria (UFSM), 97105-900, Santa Maria, RS. E-mail: andriolo@smail.ufsm.br. Autor para correspondência.

${ }^{2}$ Acadêmico do Curso de Agronomia da UFSM, Bolsista de iniciação científica do Programa Institucional de Bolsas de Iniciação Científica (PIBIC), Conselho Nacional de Desenvolvimento Científico e Tecnológico (CNPq).

${ }^{3}$ Acadêmico do Curso de Agronomia da UFSM, bolsista de iniciação científica da Fundação de Amparo à Pesquisa do Estado do Rio Grande do Sul (FAPERGS).
} 
and $T 3$, respectively, fitting well a polynomial model with estimated maximum fruit yield of $7.8 \mathrm{~kg} \mathrm{~m}^{-2}$ at a $\mathrm{N}$ concentration of $9.3 \mathrm{mmolN} \mathrm{L}^{-1}$. It was concluded that $N$ concentration of the nutrient solution affected the growth and yield of the tomato crop, but a similar effect was not observed in autumn and spring growing periods.

Key words: Lycopersicon esculentum, dry mass, fertigation, protected cultivation.

\section{INTRODUÇÃO}

O tomateiro destinado à produção de frutos para consumo in natura é uma das principais hortaliças cultivadas no mundo (NUEZ, 1995). A maior parte da produção dessa cultura é realizada em ambiente protegido empregando sistemas de produção fora do solo (CTIFL, 1995). Nesses sistemas de produção, a composição e o manejo da solução nutritiva são questões cruciais que determinam a disponibilidade hídrica e mineral da cultura ao longo do seu ciclo de desenvolvimento (CASTRO, 1999; LE BOT et al., 2002). Na composição dessas soluções, atenção especial é dada às proporções iônicas entre os cátions, especialmente $\mathrm{K}^{+}, \mathrm{Ca}^{++}$e $\mathrm{Mg}^{++}$. Quanto ao $\mathrm{N}$, concentrações elevadas são empregadas, as quais podem atingir até $20 \mathrm{mmolN} \mathrm{L}^{-1}$ (CTIFL, 1995). Essas concentrações foram assim fixadas a fim de reduzir ao máximo os riscos de deficiência de $\mathrm{N}$ para a cultura (LOPEZ, 1998). Essa prática apresenta consequiências indiretas negativas, tanto de ordem ambiental como econômica. A primeira se refere à contaminação dos mananciais hídricos pelo nitrato presente nas soluções nutritivas drenadas no ambiente. A segunda se reflete no aumento dos custos de produção, principalmente no Brasil, onde o custo dos fertilizantes é relativamente elevado quando comparado aos demais itens que determinam o custo de produção do tomateiro cultivado em substrato (ANDRIOLO et al., 1997). Entretanto, resultados recentes de literatura sugerem que a concentração de $\mathrm{N}$ nas soluções nutritivas atualmente empregadas em diversos países para o cultivo de hortaliças poderia ser reduzida, sem afetar a produtividade (SIDDIQI et al., 1998; LEBOT et al., 2002). No Brasil, são disponíveis na literatura recomendações de soluções nutritivas para o cultivo do tomateiro fora do solo, tanto em hidroponia pura (MORAES \& FURLANI, 1999) como em substratos (ANDRIOLO \& POERSCHKE, 1997; ANDRIOLO et al., 1997; RATTIN et al., 2003). A concentração de $\mathrm{N}$ nessas soluções nutritivas é semelhante àquelas empregadas nos outros países. O objetivo deste trabalho foi determinar o crescimento e a produtividade de frutos do tomateiro sob três concentrações de $\mathrm{N}$ na solução nutritiva recomendada para o cultivo dessa hortaliça em substratos, nos dois períodos anuais de cultivo em ambiente protegido no Sul do Brasil, respectivamente no outono e na primavera.

\section{MATERIAL E MÉTODOS}

Dois experimentos foram conduzidos no Departamento de Fitotecnia da Universidade Federal de Santa Maria, Rio Grande do Sul, Brasil, no interior de um túnel alto de polietileno de $180 \mathrm{~m}^{2}$. Foi empregado o híbrido plurilocular Monte Carlo, com semeaduras em 8 de fevereiro e 5 de julho de 2002, em bandejas de poliestireno com 128 células, empregando substrato comercial (Plantmax ${ }^{\circledR}$ ). Aos 36 e 40 dias após a semeadura, respectivamente no outono e na primavera, as mudas com cinco folhas definitivas foram transferidas para sacolas de polietileno contendo $5,5 \mathrm{dm}^{3}$ de substrato comercial orgânico (Plantmax $®)$, com uma planta por sacola e densidade de 3,3 plantas $\mathrm{m}^{-2}$. Em cada sacola foi instalado um tubo gotejador para o fornecimento de água e nutrientes, ajustando-se um gotejador no centro de cada sacola. As plantas foram conduzidas verticalmente com uma haste, através de fitas plásticas, e as ramificações axilares eliminadas uma vez por semana. O túnel foi ventilado nos dias ensolarados, através do soerguimento das extremidades laterais do filme de polietileno até uma altura de $1,20 \mathrm{~m}$ acima do nível do solo.

Do plantio até o final dos experimentos, os nutrientes foram fornecidos às plantas através da fertirrigação. Foi empregada como referência a solução nutritiva recomendada para o cultivo do tomateiro em substrato (ANDRIOLO, 1999), com a seguinte composição de sais macronutrientes, em mmol L-1: 5,5 de $\mathrm{KNO}_{3} ; 1,3$ de $\mathrm{KH}_{2} \mathrm{PO}_{4} ; 2,75$ de $\mathrm{Ca}\left(\mathrm{NO}_{3}\right)_{2} ; 0.75$ de $\mathrm{MgSO}_{4}$. O tratamento T2 foi igual a solução de referência, com $11,0 \mathrm{mmolN} \mathrm{L} \mathrm{L}^{-1}$. No tratamento $\mathrm{T} 1$, a concentração de nitrogênio da mesma solução nutritiva foi reduzida para 5,5mmolN L-1, mediante a substituição do $\mathrm{KNO}_{3}$ por uma dose equivalente de $\mathrm{K}_{2} \mathrm{SO}_{4}$. No tratamento $\mathrm{T} 3$, a quantidade de $\mathrm{N}$ da solução de referência (T2) foi aumentada para $15,16 \mathrm{mmolN} \mathrm{L}^{-1}$, mediante adição de $2,08 \mathrm{mmol} \mathrm{L}^{-1}$ de $\mathrm{NH}_{4} \mathrm{NO}_{3}$. A condutividade elétrica foi de 2,$3 ; 2,4$ e $2,7 \mathrm{dS} \mathrm{m}^{-1}$, nas soluções T1, T2 e T3, respectivamente. Cada parcela foi composta por 15 plantas, no delineamento inteiramente casualizado, com quatro repetições. A fertirrigação foi efetuada diariamente, com base na demanda hídrica da cultura, de forma a manter a umidade do substrato próxima daquela na capacidade máxima de retenção de água, com um coeficiente de drenagem de aproximadamente 30\% (ANDRIOLO, 2002). 
Quatro plantas de cada tratamento foram coletadas aleatoriamente, uma em cada parcela, aos $33,48,55,62,69,76$ e 83 dias após o plantio (DAP) no outono e aos 55, 62, 69, 78, 85 e 92 DAP na primavera. Imediatamente após a coleta, os órgãos vegetativos (folhas, caule, pecíolos, inflorescências e pedúnculos) e os frutos foram separados. O material vegetal foi submetido à secagem em estufa de circulação forçada, na temperatura de $60^{\circ} \mathrm{C}$, até peso constante, para determinar a massa seca. Os frutos maduros foram colhidos e pesados, para determinação da produtividade da cultura. No outono, foi feita uma única coleta de todos os frutos no final do experimento, aos 83 DAP. Na primavera, a colheita iniciou aos 86 DAP e foi concluída aos 105 DAP, quando o experimento foi encerrado. As médias relativas às variáveis de crescimento e desenvolvimento medidas em cada coleta foram submetidas à análise da variância, sendo a significância das diferenças testada pelo teste de Duncan, em nível de probabilidade de erro de $5 \%$. Os dados de produtividade de frutos foram submetidos à análise de regressão, tendo-se retido o modelo com maior coeficiente de determinação e com diferença significativa em relação ao modelo com número de variáveis imediatamente inferior. Os resultados de produtividade de frutos foram considerados representativos de todo o ciclo da cultura, com base nas conclusões de LOPES et al., (2001).

\section{RESULTADOS E DISCUSSÃO}

A evolução do número de folhas nas plantas cultivadas no outono foi similar nos três tratamentos entre 48 e 69 dias após o plantio (DAP) (Figura 1a). Nas duas últimas coletas, essa variável apresentou valores inferiores em T3, com diferença de T2 na última coleta. Os valores médios contados na última coleta foram de 86,58; 88,24 e 84,08 folhas $\mathrm{m}^{-2}$, respectivamente em T1, T2 e T3. Na primavera, valores inferiores foram também observados nas plantas de T3, dos 69 DAP até a última coleta efetuada (Figura 1b). Os valores médios na última coleta foram de 91,$57 ; 91,57$ e 84,07 folhas $\mathrm{m}^{-2}$, respectivamente em T1, T2 e T3. A evolução do número de frutos no outono foi similar entre 33 e 85 DAP (Figura 1c), atingindo na última coleta valores de $60 ; 63$ e 59 frutos $\mathrm{m}^{-2}$ em T1, T2 e T3, respectivamente. Na primavera, a evolução do número de frutos mostrou valores mais elevados nas plantas de T1, seguidos por T2 e T3 (Figura 1d), com diferenças significativas na última coleta efetuada, quando os valores dessa variável foram de 59; 52 e 48 frutos $\mathrm{m}^{-2}$ em T1, T2 e T3, respectivamente.
A evolução da massa seca de folhas foi similar entre os tratamentos no outono (Figura 2a). No período até $62 \mathrm{DAP}$, a taxa média de crescimento das folhas das plantas nos três tratamentos foi de 1,67; 1,84 e 2,07gMS m m $^{-2} \mathrm{dia}^{-1}$ em T1, T2 e T3, respectivamente, situando-se próxima de zero desta coleta até o final do experimento. Na primavera, a taxa média de crescimento das folhas foi de 2,72; 2,19 e 1,93gMS m $\mathrm{g} \mathrm{dia}^{-1}$, respectivamente, em T1, T2 e T3, até 78 DAP (Figura 2b). A evolução da massa seca do caule no outono não se mostrou afetada pelos tratamentos até a coleta efetuada aos 76 DAP (Figura 2c). Na primavera, a evolução do crescimento do caule em T3 mostrou valores inferiores à testemunha na maior parte do período experimental. Entretanto, as variações observadas entre as sucessivas coletas não permitiram detectar resposta significativa entre os tratamentos. A massa seca de frutos evoluiu de forma similar nos três tratamentos no experimento de outono, cujos valores na última coleta foram de 315,10; 327,26 e 304,11g $\mathrm{m}^{-2}$, para T1, T2 e T3, respectivamente (Figura 2e). Evolução semelhante foi observada na primavera, até a coleta feita aos 78 DAP (Figura 2f). Nas duas últimas coletas deste experimento, os valores dessa variável foram inferiores nas plantas de T3, cujas médias finais foram de 330,67; 332,16e 246,67. $\mathrm{g} \mathrm{m}^{-2}$, respectivamente.

A produtividade de frutos atingiu valores médios de 5,4; 5,5 e 5,2 $\mathrm{kg} \mathrm{m}^{-2}$ no outono e de 5,9; 7,1 e $5,4 \mathrm{~kg} \mathrm{~m}^{-2}$ na primavera, respectivamente para $\mathrm{T} 1, \mathrm{~T} 2 \mathrm{e}$ T3. No outono, o efeito do $\mathrm{N}$ sobre essa variável não foi significativo (Figura 3). Na primavera, os dados ajustaram-se a um modelo do tipo polinomial, com produtividade máxima estimada de $7,8 \mathrm{~kg} \mathrm{~m}^{-2}$ na dose de 9,3mmolN L-1.

Os resultados de literatura descrevendo os efeitos da carência de nitrogênio em plantas de tomateiro mostram o aumento da massa seca alocada para as raízes como uma das primeiras alterações (RUFTY et al., 1988), seguida por uma redução no crescimento e desenvolvimento das folhas (CHAPIN et al., 1998) e finalmente queda na produção de massa seca de frutos (LE BOT et al., 2002). A maior parte desses resultados foi obtida em culturas de ciclo longo, de oito a dez meses, e durante o período de produção de frutos. Durante o período de produção dessas culturas, o índice de área foliar é mantido em valores na faixa entre $3,0-3,5$ através do desfolhamento periódico (NUEZ, 1995; CTIFL, 1995), com base nos trabalhos pioneiros de ACOCK et al. (1978). Através desse procedimento, a fração da massa seca total presente nos frutos atinge valores superiores a $60 \%$ (HEUVELINK \& BUISKOOL, 1995) e o crescimento da planta se ajusta a uma relação com a 


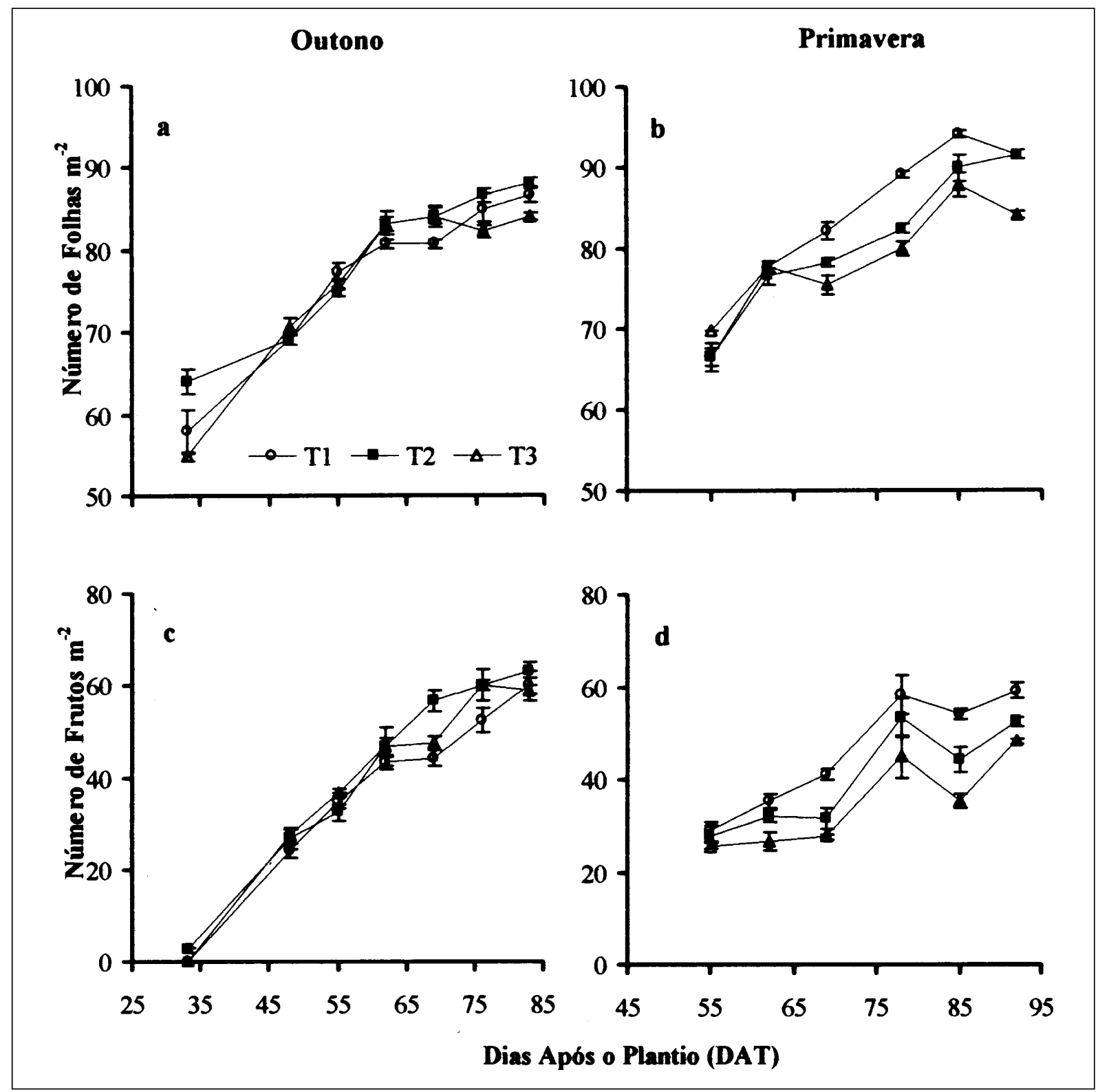

Figura 1 - Número de folhas (a,b) e de frutos (c,d) de plantas de tomateiro cultivadas em substrato com três doses de $\mathrm{N}$ na solução nutritiva, no outono $(\mathrm{a}, \mathrm{c})$ e na primavera $(\mathrm{b}, \mathrm{d}) .\left(5,5 ; 11,0\right.$ e $15,16 \mathrm{mmolN} \mathrm{L}^{-1}$ em T1, T2 e T3, respectivamente). Santa Maria, UFSM, 2002.

quantidade de N absorvido (LEMAIREet al., 1997). Nessas condições, os efeitos da restrição de $\mathrm{N}$ podem ser explicados por modifiações nos padrões de alocação de massa seca entre os órgãos da planta, o que explicaria os resultados de LE BOT et al. (2002), os quais observaram, em uma cultura de tomateiro, que os efeitos da supressão de $\mathrm{N}$ na solução nutritiva somente passaram a ser observados após quatro semanas de aplicação do tratamento. Os resultados deste trabalho foram obtidos em condições que se afastam daquelas relativas aos experimentos descritos na literatura. Aduração do ciclo da cultura do tomateiro em ambiente protegido no Sul do Brasil situa-se em torno de 120-140 dias a partir do plantio, tanto no outono como na primavera, e a massa seca alocada para os frutos dificilmente ultrapassa a fração de $50 \%$ (ANDRIOLO et al., 1998; STEFANELLO, 2003). Isso significa, que, nessas condições, a demanda por $N$ é menor do que aquela relativa às culturas descritas nos experimentos da literatura. É importante ressaltar ainda que, nos atuais experimentos, não houve a supressão do $\mathrm{N}$ na 


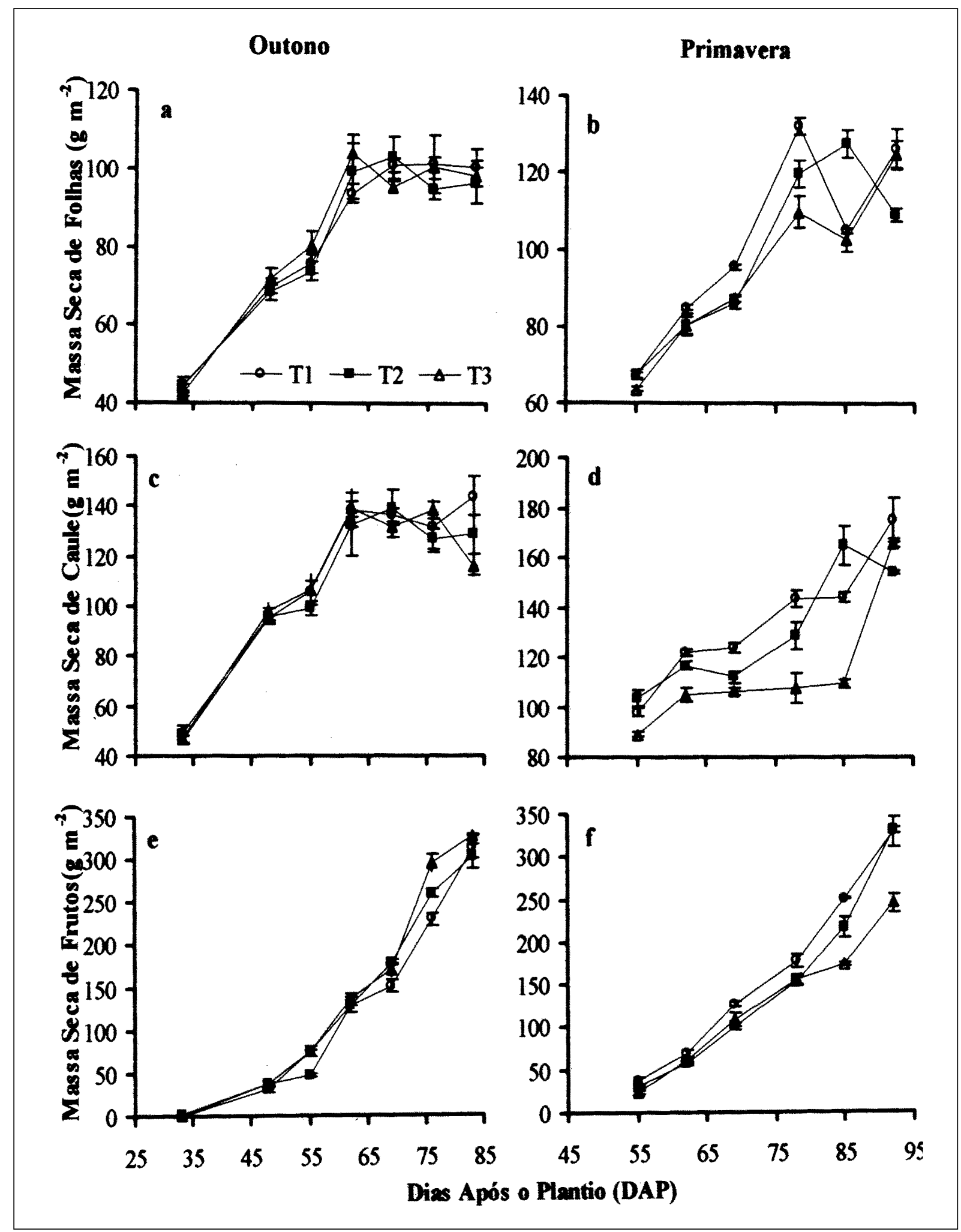

Figura 2 - Massa seca de folhas $(a, b)$, de caule $(c, d)$ e de frutos $(e, f)$ de plantas de tomateiro cultivado em substrato com três concentrações de $\mathrm{N}$ na solução nutritiva, no outono (a,c,e) e na primavera (b,d,f). $\left(5,5 ; 11,0\right.$ e $15,16 \mathrm{mmolN} \mathrm{L}^{-1} \mathrm{em}^{-}$ T1, T2 e T3, respectivamente). Santa Maria, UFSM, 2002. 


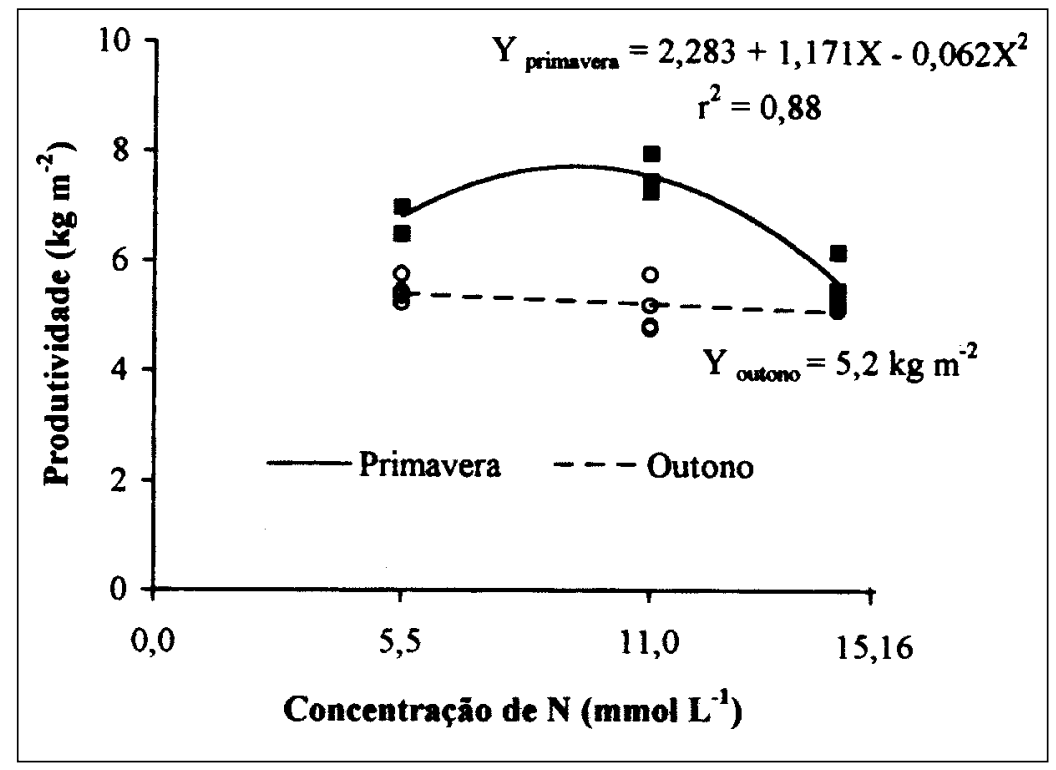

Figura 3 - Produtividade de frutos de tomateiro cultivado em substrato com três doses de N na solução nutritiva, no outono e na primavera. Santa Maria, UFSM, 2002 .

solução nutritiva, apenas sua redução na dose inferior. Os resultados da massa seca de folhas, os quais foram pouco afetados pelos tratamentos em ambos os experimentos, sugerem que as quantidades de $\mathrm{N}$ fornecidas pela dose inferior (T1) ainda foram suficientes para sustentar o crescimento da massa seca. Essa conclusão decorre do fato de que o crescimento das folhas é uma das primeiras variáveis da planta a ter seu crescimento afetado pela deficiência de N(LEMAIRE et al., 1997).

O efeito dos tratamentos sobre a massa seca e produtividade de frutos foram decorrentes principalmente das variações no número de folhas e de frutos fixados. Esse fenômeno pode ser visualizado de forma clara no experimento de primavera. A partir da coleta feita aos 69 DAP, o número de folhas por planta passou a ser inferior nas plantas de T3 (Figura 1b). Esse resultado é atribuído à senescência e morte das folhas inferiores do dossel, a qual não afetou a acumulação de massa seca de folhas da planta inteira (Figura 2b), sugerindo ter havido uma compensação pelas folhas localizadas na parte superior do dossel. Valores inferiores foram observados também no número de frutos fixados pelas plantas de T3, o que sugere que a concentração mais elevada de $\mathrm{N}$ afetou negativamente essa variável (Figura 1d). Tem sido relatado na literatura que doses excessivas de $\mathrm{N}$ favorecem o crescimento vegetativo das culturas, reduzem a fixação de frutos, retardando o início da frutificação e reduzindo a produtividade (CTIFL, 1995; NUEZ, 1995). Esses fenômenos são ainda agravados em condições de baixo suprimento de fotoassimilados (ANDRIOLO et al,. 1998), o que pode explicar a baixa produtividade das plantas de T3 na primavera. No período de crescimento e desenvolvimento das plantas deste experimento, ocorreram períodos de vários dias sucessivos com nebulosidade, reduzindo os valores médios de radiação solar global para $8,92 \mathrm{MJ} \mathrm{m}^{-2} \mathrm{dia}^{-1}$, próximos, portanto, do limite trófico dessa cultura (BURIOL et al., 2000). Os resultados apresentados indicaram que não houve uma resposta única aos tratamentos no outono e na primavera. Esse fato está relacionado com fatores ambientais e fisiológicos que interferem tanto na disponibilidade de nutrientes como na demanda de absorção pela planta. No cultivo em substratos, tem sido demonstrado que a disponibilidade de nutrientes às plantas depende, entre outros fatores, da concentração iônica da solução nutritiva, das reações que ocorrem no interior do substrato e também da absorção de água pela cultura, a qual afeta a concentração salina no interior do substrato (DE RIJCK \& SCHREVENS, 1998). Quando são empregados substratos orgânicos com alta CTC, é provável que quantidades consideráveis de nutrientes permaneçam disponíveis às plantas no interior do substrato, mesmo sob baixos valores de CE na solução nutritiva drenada $\left(<1,0 \mathrm{dS} \mathrm{m}^{-1}\right)$. Isso significa que o manejo correto da fertirrigação dessa cultura deve ser feito levando-se em conta as características do material empregado como subtrato e também o volume empregado para cada planta no interior da sacola. No outono, a taxa de crescimento e a demanda de $\mathrm{N}$ são mais elevadas nos estádios iniciais de desenvolvimento da cultura, quando as disponibilidades radiativa e térmica são também mais elevadas (BURIOL et al., 2000). Por esse motivo, os resultados sugerem que, no outono, a concentração de $\mathrm{N}$ empregada na fertirrigação poderia ser reduzida nas fases finais do ciclo da cultura, para reduzir as perdas desse nutriente por drenagem. Na primavera, as condições ambientais evoluem de forma inversa e são mais favoráveis ao crescimento nos estádios finais de desenvolvimento da cultura. Nesse período, a demanda hídrica da 
cultura também é mais elevada, o que implica irrigações mais freqüentes e maior lixiviação de nutrientes por drenagem, diminuindo a disponibilidade de $\mathrm{N}$ às plantas. $\mathrm{O}$ monitoramento de sua concentração nessa fase do ciclo de produção se mostra necessária, para evitar que a $\mathrm{CE}$ atinja valores muito baixos e provoque queda na produtividade.

\section{CONCLUSÕES}

Os resultados indicaram que concentrações de $\mathrm{N}$ na solução nutritiva acima ou abaixo daquela recomendada para o cultivo do tomateiro em substrato afetam o crescimento e a produtividade da cultura. Entretanto, não foi observada resposta similar nos dois ciclos de cultivo que foram objeto dos experimentos conduzidos. Isso significa que o manejo correto da fertirrigação dessa cultura deve ser feito levando-se em conta também outros fatores determinantes do crescimento, especialmente as condições ambientais associadas com a época do ano.

\section{REFERÊNCIAS BIBLIOGRÁFICAS}

ACOCK B. et al. The contribution of leaves from different levels within a tomato crop to canopy net photosynthesis: an experimental examination of two canopy models. Journal of Experimental Botany, Oxford, v.29, n.111, p.815-827, 1978.

ANDRIOLO, J.L. et al. Crescimento e desenvolvimento do tomateiro cultivado em substrato com fertirrigação. Horticultura Brasileira, Brasília, v.15, n.1, p.28-32, 1997.

ANDRIOLO, J.L.; POERSCHKE, P.R. Cultivo do tomateiro em substratos. Santa Maria: UFSM - Centro de Ciências Rurais, 1997. 12p. (Informe Técnico, 2).

ANDRIOLO, J.L. et al. Growth, development and dry matter distribution of a tomato crop as affected by environment. Journal of Horticultural Science \& Biotechnology, Ashford Kent, v.73. p.125-130, 1998.

ANDRIOLO, J.L.Fisiologia das culturas protegidas. Santa Maria : UFSM, 1999. 142p.

ANDRIOLO, J.L. Olericultura geral: princípios e técnicas. Santa Maria : UFSM, 2002. 158p.

BURIOL, G.A., et al. Disponibilidade de radiação solar nos meses mais frios do ano para o cultivo do tomateiro no estado do Rio Grande do Sul. Pesquisa Agropecuária Gaúcha, Porto Alegre, v.6, n.1, p. 113-120, 2000.

CASTRO, A.C. Solución nutritiva: princípios básicos, comportamiento e interacción de los distintos elementos. In : MILAGROS, M.F.; GÓMEZ, I.M.C. (Ed.). Cultivos sin suelo II. Curso Superior de Especialización. 2.ed.
Almería: DGIFA-FIAPA-Caja Rural de Almería, 1999. p.229286.

CHAPIN, F.S.III.; WALTER, C.H.S.; CLARKSON, D.T. Growth response of barley and tomato to nitrogen stress and its control by absisic acid, water relations and photosynthesis. Planta, Berlin, n.173, p.352-366, 1998.

CTIFL. Centre Technique Interprofessionel des Fruits e des Légumes. Maîtrise de la conduite climatique. Paris : CTIFL, 1995. 127p.

DE RIJCK, G; SCHREVENS, E. Distribution of nutrients and water in rockwool slabs. Scientia Horticulturae, Amsterdan, n.72, p.277-285, 1998.

HEUVELINK, E.; BUISKOOL, R.P.M. Influence of sink-source interaction on dry matter production in tomato. Annals of Botany, Oxford, n.75, p.381-389, 1995.

LE BOT, J.; JEANNEQUIN, B.; FABRE, R. Growth and nitrogen status of soilless tomato plants following nitrate withdrawal from the nutrient solution. Annals of Botany, Oxford, n.88, p.361-370, 2002.

LEMAIRE, G.; GASTAL, F.; PLENET, D. Dynamics of N uptake and $\mathrm{N}$ distribution in plant canopies. In: LEMAIRE, G.; BURNS, I.G. (Ed.). Diagnosis of the nitrogen status in crops. Paris : INRA, 1997. p.15-29.

LOPES, S.J. et al. Técnicas experimentais para tomateiro tipo salada sob estufas plásticas. Ciência Rural, Santa Maria, v.28, n.2, p.193-197, 2001

LOPEZ, C.C. Fertirrigación. Aspectos básicos In : LOPEZ, C.C. (Ed.). Fertirrigación: cultivos horticolas y ornamentales. Madrid: Mundi-Prensa, 1998. p. 63-79.

MORAES, C.A.G de; FURLANI, P.R. Cultivo de hortaliças de frutos em hidroponia em ambiente protegido. Informe Agropecuário, Belo Horizonte, v.20, n. 200/201, p.105-113, 1999.

NUEZ, F. El cultivo del tomate. Madrid : Mundi-Prensa, 1995. 793p.

RATTIN, J.E.; ANDRIOLO, J.L.; WITTER, M. Acumulação de massa seca e rendimento de frutos de tomateiro cultivado em substrato com cinco doses de solução nutritiva. Horticultura Brasileira, Brasília, v.21, n.1, p.26-30, 2003.

RUFTY, T.W.J.; HUBER, S.C.; VOLK, R.J. Alteration of leaf carbohydrate metabolism in response to nitrogen stress. Plant Physiology, Washington, n.88, p.725-730, 1988.

SIDDIQI, M.Y. et al. Growth of a tomato crop at reduced nutrient concentrations as a strategy to limit eutrophication. Journal of Plant Nutrition, Georgia, n.21, p.1879-1895, 1998.

STEFANELlO, M.O. Alta densidade com desfolhamento do tomateiro em ambiente protegido e seus efeitos sobre o desenvolvimento, crescimento e produtividade. 2003. 57f. Dissertação (Mestrado em Agronomia) - Curso de Pósgraduação em Agronomia, Universidade Federal de Santa Maria. 